\title{
Hepatitis B: transmission and natural history
}

\author{
R P Perrillo
}

Gastroenterology Section,

Veterans

Administration

Medical Center,

Washington

University,

St Louis, USA

R P Perrillo

Correspondence to:

Dr R P Perrillo,

Veterans Administration

Medical Center (111JC)

915 North Grand Boulevard

St Louis, Missouri 63106,

USA.

\begin{abstract}
This paper reviews the transmission and natural history of hepatitis $B$ viral infection. Means of transmission are compared by geographical region, and the association with risk factors is described. Long term outcome and overall survival are documented, and the need for universal screening programmes is discussed. (Gut 1993; supplement: S48-S49)
\end{abstract}

\section{Epidemiology and transmission}

The prevalence of hepatitis $B$ virus (HBV) infection is highest in developing countries in Asia, Africa, and the Pacific Islands and lowest in developed countries in North America, western Europe, and Australasia (Table). ${ }^{1}$ Methods of transmission vary geographically

TABLE Worldwide distribution of hepatitis $B$ virus infection

\begin{tabular}{llll}
\hline & Endemic status & & \\
\cline { 2 - 4 } & Low & Intermediate & High \\
\hline $\begin{array}{c}\text { Prevalence; } \\
\begin{array}{c}\text { Chronic infection } \\
\text { Total infection }\end{array}\end{array}$ & $<2 \%$ & & \multicolumn{1}{l}{$8-15 \%$} \\
Distribution & $<20 \%$ & $20 \%$ & $>60 \%$ \\
& North America & Eastern Europe & Southeast Asia \\
& Western Europe & Southern Europe & China \\
& Soviet Union & Philippines \\
& Australia & Central Asia & Indonesia \\
& New Zealand & Japan & Middle East \\
& South America & South America & Africa \\
& (southern) & Amazon Basin \\
& & & Pacific Islands \\
& & & Arctic (Eskimo) \\
\hline
\end{tabular}

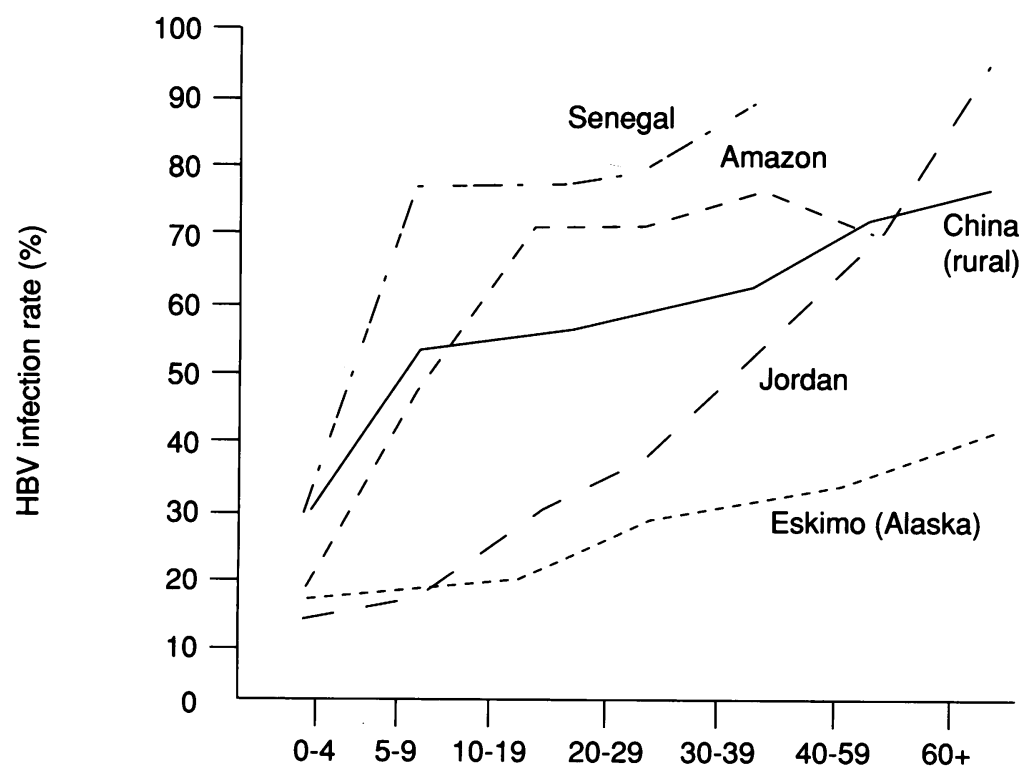

Age group

Figure Age specific seroprevalence of hepatitis $B$ virus (HBV) infection in selected populations with a high endemicity of infection. ${ }^{1}$ and are generally related to the incidence of infection. In areas of high $\mathrm{HBV}$ incidence, transmission is usually vertical from infected mother to child, or horizontal within families (Figure). ${ }^{1}$ In intermediate areas of prevalence, HBV is spread horizontally, with the highest rate of infection occurring among older children, adolescents, and adults. In areas of low prevalence, HBV is primarily a disease of adolescents and young adults and is transmitted sexually or parenterally.

HBV transmission through exchange of body fluids and blood contact, occurs in the following exposure settings: (a) perinatal infection (pregnancy or childbirth); (b) sexual contact (homosexual or heterosexual); (c) inadvertent transmission of contaminated blood via exchange of blood products (for example, transfusion, dialysis), shared needles in intravenous drug abusers, and needlestick type and other open wound injuries (for example, accidents, violence).

Nearly 300000 cases of acute HBV infection occur in the United States each year. While most of these are short lived, chronic infection occurs in approximately $2-5 \%$ of instances. Hepatitis B is seldom a fulminant disease, but when this occurs mortality rates are high unless liver transplantation is done. The epidemiology of acute $\mathrm{HBV}$ infection in the United States has changed over the past decade, with a major decline observed in male homosexuals and health care workers and an increase in heterosexually promiscuous and intravenous drug user populations. Irrespective of the exposure setting, recipients of $\mathrm{HBV}$ antigen $(\mathrm{HBeAg})$ reactive donors are three to fourfold more likely to develop infection. The risk of persistent $\mathrm{HBV}$ infection in children is inversely related to the age of the child at initial infection. Therefore, the greatest impact on prevention of hepatitis B will result from universal screening of pregnant women and immunoprophylaxis of exposed infants, and the integration of $\mathrm{HBV}$ vaccine into current childhood immunisation schedules.

\section{Long term outcome}

Worldwide, it has been estimated that over 250000 people die annually from HBV associated acute and chronic liver disease. ${ }^{1}$ In a study correlating outcome with the initial histological diagnosis, the estimated five year survival rate was $97 \%$ for chronic persistent hepatitis, $86 \%$ for chronic active hepatitis, and $55 \%$ for chronic active hepatitis with cirrhosis. ${ }^{2}$ Recently, investigators in the Netherlands have described an overall five year survival of $14 \%$ in patients with decompensated chronic 
hepatitis B. ${ }^{3}$ Prospective studies in Asia have shown that HBV carriers have at least a 200 fold greater risk of developing hepatocellular carcinoma than those who do not carry the virus. ${ }^{4}$ Moreover, it has been estimated that the lifetime risk of death from hepatocellular carcinoma or cirrhosis, or both is between 40 and $50 \%$ for men, and the risk of death from liver disease is approximately $15 \%$ for women. The exact frequency of transformation to cirrhosis is not known, but this generally occurs insidiously and without a noticeable change in symptoms. Several studies have shown that even mild forms of histological injury, such as chronic persistent hepatitis, can progress to chronic active hepatitis and cirrhosis in as many as one third of patients when viral replication is sustained.

1 Margolis HS, Alter MJ, Hadler SC. Hepatitis B: Evolving epidemiology and implications for control Sem Liver Dis 1991; 11: 84-92.

2 Weissberg J, Andres LL, Smith CI, et al. An analysis of 379 patients. Ann Intern Med 1984; 101: 613-16.

3 de Jongh FE, Janssen HI A, de Man RA, Hop WCJ, Schalm SW, van Blankenstein $M$. Survival and prognostic indicators in HBsAg-positive cirrival and prognostic indicators in $\mathrm{HBsAg}$-positive cirrhosis of the liver. The 103: $1630-5$

4 Beasley RP, Hwang LY. Epidemiology of hepatocellular carcinoma. In: Vyas GN, Dienstag JL, Hoofnagle JH, eds. Viral hepatitis and liver disease. New York: Grune and Stratton, 1983: 209-24. 